\title{
Measurement of the black globe temperature to estimate the MRT and WBGT indices using a smaller diameter globe than a standardized one: Experimental analysis
}

\author{
Carlos Vargas-Salgado ${ }^{a}$, Cristian Chiñas-Palacios ${ }^{b}$, Jesús Aguila-León ${ }^{c}$, David \\ Alfonso-Solar ${ }^{\text {d }}$ \\ ${ }^{\mathrm{a} D e p a r t m e n t}$ of Electrical Engineering, Universitat Politècnica de València, Spain. \\ carvarsa@upvnet.upv.es \\ ${ }^{\mathrm{b}, \mathrm{c}}$ Department of Water and Energy Studies, Universidad de Guadalajara, Mexico, \\ jesus.aguila@academicos.udg.mx, daniel.chinas@academicos.udg.mx. \\ ${ }^{\mathrm{d} U n i v e r s i t a t ~ P o l i t e ̀ c n i c a ~ d e ~ V a l e ̀ n c i a, ~ D e p a r t m e n t ~ o f ~ A p p l i e d ~ T h e r m o d y n a m i c s . ~ V a l e n c i a ~(S p a i n) . ~}$ \\ daalso@iie.upv.es
}

\begin{abstract}
Heat stress can affect negatively human performance, behavior and even health, therefore, mean radiant temperature (MRT) and wet-bulb globe temperature (WBGT) measurement and monitoring should be obtained for any environment in which people are constantly exposed. The aim of this work is to compare the globe thermometer temperature $\left(t_{g}\right)$, used for calculating both MTR and WBGT, using a smaller globe compared to a standardized diameter. For such purpose, a prototype has been designed. The device consists of an Arduino MEGA board, three temperature sensors, two black globes (Copper globe, matt black painted) and an anemometer. As an effort to use a device with a globe easier to handle in a real measuring device, a $9 \mathrm{~cm}$ diameter globe has been used which has a smaller diameter than a standardized one $(15 \mathrm{~cm})$; the third temperature sensor is used to measure the air temperature. MRT monitoring tests were carried out using the proposed prototype, collected data were compared between the smaller and the standardized diameter globes measurements according to UNE EN ISO 7723 and NTP 322 recommendations. Results of this work show that it is possible to use a smaller diameter globe in a heat stress monitor, with an acceptable margin of error compared to a standardized size globe.
\end{abstract}

Keywords: Heat stress monitor; Globe temperature; MRT; Arduino. 
Measurement of the black globe temperature to estimate the MRT index using a smaller diameter globe than a standardized one: experimental analysis

\section{Introduction}

Contact to heat stress environments can produce health problems (Deschenes, 2014; Enander \& Hygge, 1990; Fishman, Carrillo, \& Russ, 2019; Gasparrini et all., 2017) and many times a heat stress index monitor cannot be representative (Maurya, Haque, Kumar, \& Diwakar, 2019). To regulate human safety and health in working environments, UNE EN ISO 7726 regulations and NTP 322 propose a standardized method for heat stress index measurement such as MRT and WBGT, using the globe thermometer temperature.

If an MRT or WBGT monitor is designed and built according to UNE EN ISO 7726 and NPT 322 specifications, using a 15 centimeters temperature globe, it will be difficult to handle, prone to breakage and heavier. The objective of this work is to compare the globe thermometer temperature $\left(\mathrm{t}_{\mathrm{g}}\right)$, used for calculating both MTR and WBGT, using a smaller globe compared to a standardized diameter globe.

\section{Methodology}

In order to compare the temperature thermometer globe sensor used for calculating both MTR and WBGT, a low-cost heat stress monitor index have been designed and built. The device consists of an Arduino MEGA board, four temperature sensors (one DTH22 and three DS1802), two black globes (Copper globe, matt black painted), a relative humidity sensor (DHT22) and a cups anemometer. One globe is $9 \mathrm{~cm}$ diameter which thas a smaller diameter than the standardized globe $(15 \mathrm{~cm})$, another temperature sensor is used to measure air temperature.

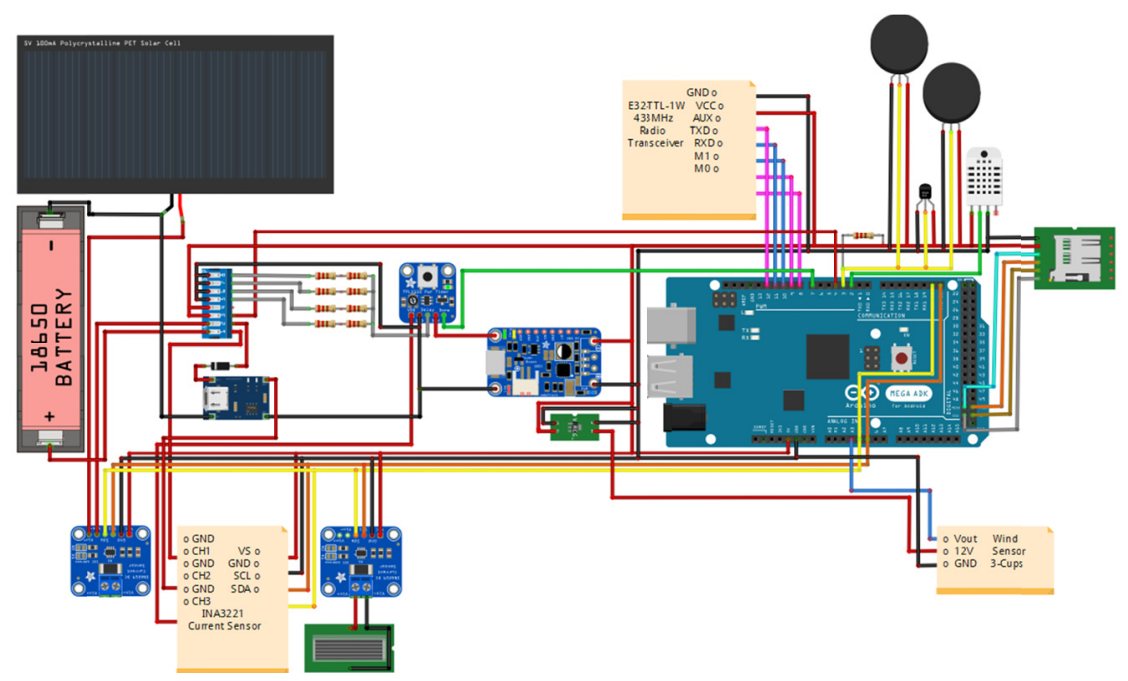

Figure 1. Proposed WBGT monitor prototype general scheme 
As an effort of developing a cheap heat stress monitor, Figure 1 shows the general scheme of the prototypes. Both prototypes ( 9 and $15 \mathrm{~cm}$ diameter globe) were installed at the Polytechnic University of Valencia, to measuring continuously from February 2 to June 05, 2019, Figure 2 shows photographs of the deployed prototypes.
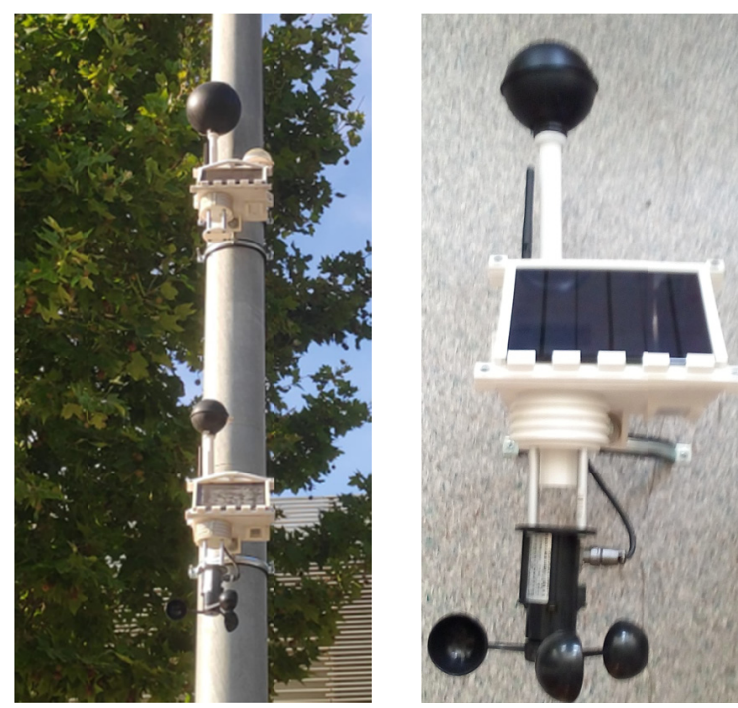

Figure 2. Proposed WBGT monitor prototype implementation

To obtain the WBGT index there are two possible situations, index estimation for indoor of for outdoor environments (Mendaza, 1993; NTP 322, 1999). According to NTP 322, WBGT index calculation for indoor (or outdoor without solar irradiance) and outdoor (with solar irradiance) environments is carried out by Equation 1 and Equation 2.

$$
\begin{array}{ll}
W B G T_{\text {indoor }}=0.7 t_{n w b}+0.3 t_{g} & \text { Equation 1 } \\
W B G T_{\text {outdoor }}=0.7 t_{n w b}+0.2 t_{g}+0.1 t_{a} & \text { Equation 2 }
\end{array}
$$

Where, $t_{n w b}$ is the natural wet-bulb temperature, $t_{g}$ is the globe temperature and $t_{a}$ is the dry air temperature. $t_{n w b}$ is measured by a thermometer with its bulb covered with a wettened cotton, without shields for avoiding wind or radiation and under natural ventilation conditions and can be calculated using the Equation 3 (Hunter and Minyard 1999).

$$
t_{n w b}=t_{w}+0.0021 S-0.42 v_{w}+1.93 \quad \text { Equation } 3
$$

Where, $t_{w}$ is the psychometric temperature of wet bulb, $S$ is solar irradiation and $v_{w}$ the wind velocity. $t_{w}$ can be calculated using air by means of Equation 4, using air 
Measurement of the black globe temperature to estimate the MRT index using a smaller diameter globe than a standardized one: experimental analysis

temperature $\left(t_{a}\right)$ and relative humidity (RH\%) measurements at standard sea level, as propose to (Stull, 2011).

$t_{w}=t_{a} \tan ^{-1}\left[0.151977(R H \%+8.131659)^{1 / 2}\right]+\tan ^{-1}\left(t_{a}+R H \%\right)-\tan ^{-1}(R H \%-$

$1.676331)+0.00391838(R H \%)^{3 / 2} \tan ^{-1}(0.023101 R H \%)-4.686035 \quad$ Equation 5

Mean radiant temperature (MRT) $\bar{t}_{r}$ is calculated according to (UNE ISO 7726, 2002) using Equations 6 to 9. Equations 6 is used for forced convection, and Equation 7 for natural convection when globe diameter is less than $15 \mathrm{~cm}$. Equations 8 is used for forced convection, and Equation 9 for natural convection when globe diameter is equal to $15 \mathrm{~cm} . \bar{t}_{r}$ depend on the globe temperature $t_{g}$, the thermal emissivity of the balloon $\varepsilon_{g}$, the diameter of the balloon $D$ and the air temperature $t_{a}$.

$$
\begin{array}{lll}
\bar{t}_{r}=\left[\left(t_{g}+273\right)^{4}+\frac{1.1 \times 10^{8}\left(w_{\text {speed }}\right)^{0.6}}{\varepsilon_{g} D^{0.4}}\left(t_{g}-t_{a}\right)\right]^{1 / 4}-273 & \text { Equation 6 } \\
\bar{t}_{r}=\left[\left(t_{g}+273\right)^{4}+\frac{0.25 \times 10^{8}}{\varepsilon_{g}}\left(\frac{\left|t_{g}-t_{a}\right|}{D}\right)^{1 / 4}\left(t_{g}-t_{a}\right)\right]^{1 / 4}-273 & \text { Equation 7 } \\
\bar{t}_{r}=\left[\left(t_{g}+273\right)^{4}+2.5 \times 10^{8} x\left(w_{\text {speed }}\right)^{0.6}\left(t_{g}-t_{a}\right)\right]^{1 / 4}-273 & \text { Equation 8 } \\
\bar{t}_{r}=\left[\left(t_{g}+273\right)^{4}+0.4 \times 10^{8} x\left|t_{g}-t_{a}\right|^{1 / 4} x\left(t_{g}-t_{a}\right)\right]^{1 / 4}-273 \text { Equation 9 }
\end{array}
$$

The choice between natural or forced convection equations depends on the thermal transfer coefficient $\left(h_{c g}\right)$ value. Using Equation 10 and 11 respectively, $h_{c g}$ has been calculated for both forced and natural convection. If the thermal transfer coefficient for forced convection is greater than that natural convection, then forced convection equation for MRT should be used, and vice versa.

$$
\begin{aligned}
& h_{c g}=6.3\left(\frac{w_{\text {speed }}^{0.6}}{D^{0.4}}\right) \\
& h_{c g}=1.4\left(\frac{\Delta T}{D}\right)^{1 / 4}
\end{aligned}
$$

Equation 10

Equation 11

\section{Results}

Figure 3a shows a scatter plot comparing the globe temperature measurements obtained between the $9 \mathrm{~cm}$ and $15 \mathrm{~cm}$ globes. A calibration curve, shown in Equation 11, was obtained by means of the linear regression (Figure 3a). The results of the $9 \mathrm{~cm}$ measurements values correction are shown in Figure $3 b$, where $t_{g, 15 \mathrm{~cm}}, t_{g, 9 \mathrm{~cm}}$ and $\mathrm{t}_{\mathrm{g}, 9 \mathrm{~cm} \_ \text {corrected }}$ are compared in a typical day. 


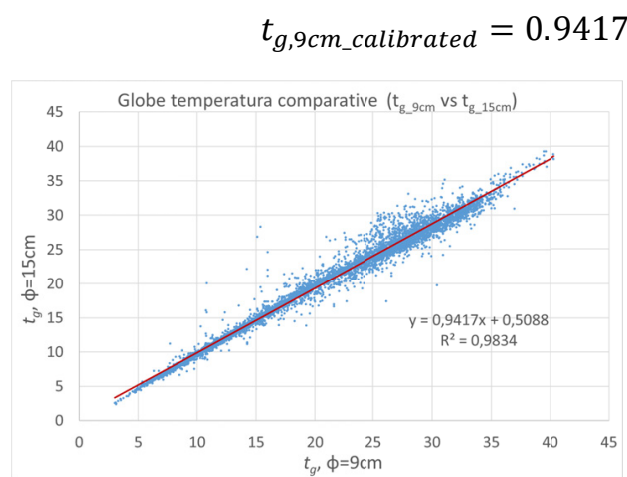

(a)

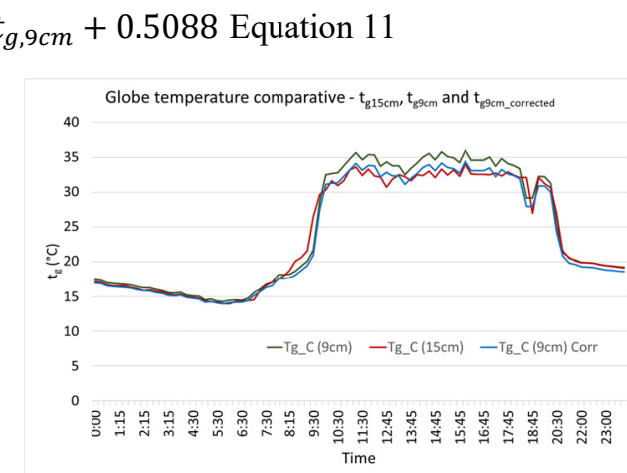

(b)

Figure 3. (a) Scatter graph between $9 \mathrm{~cm}$ prototype measurements and standardized device and (b), curves obtained for a normal day using calibrated measurements.

Figure 4 shows the scatter plot and measurement curves for the MRT. The dispersion between MRT measurements is greater compared to globe temperature measurements. Equation 12 shows the calibration curve obtained by linear regression for measurements made using the $9 \mathrm{~cm}$ globe device.

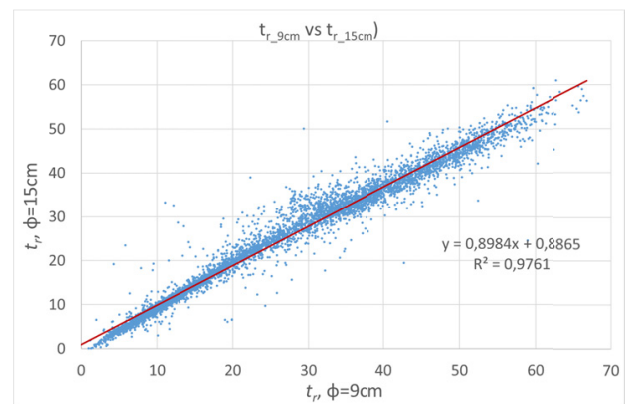

(a)

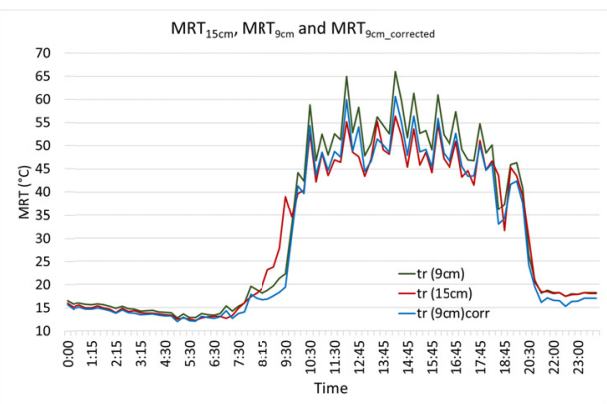

(b)

Figure 4. (a) Scatter graph between $9 \mathrm{~cm}$ prototype measurements and standardized device and (b), curves obtained for a normal day using calibrated measurements for MRT.

$$
\bar{t}_{r, 9 c m_{-} \text {calibrated }}=0.8984 \bar{t}_{r, 9 \mathrm{~cm}}+0.8865 \quad \text { Equation } 12
$$

Similarly, Figure 5 shows both the scatter plot and the curves obtained for WBGT estimates and Equation 13 shows the calibration curve obtained. It is remarkable how WBGT measurements have the lowest degree of dispersion, compared to globe temperature and MRT measurements. 
Measurement of the black globe temperature to estimate the MRT index using a smaller diameter globe than a standardized one: experimental analysis

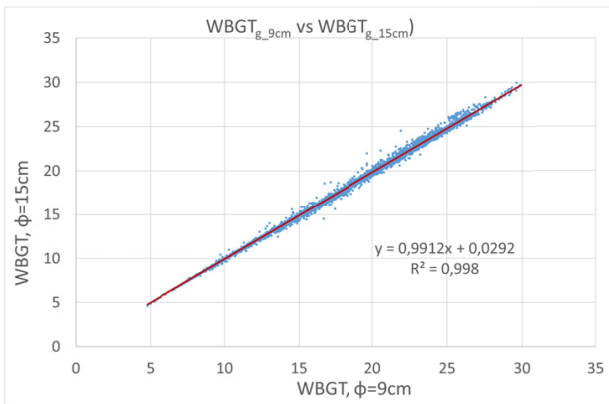

(a)

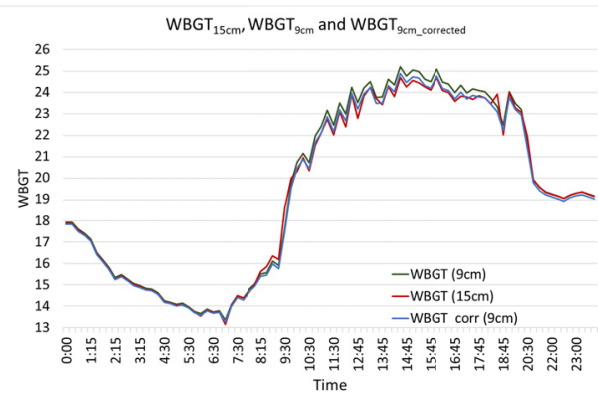

(b)

Figure 5. (a) WBGT measurements scatter plot between $9 \mathrm{~cm}$ and $15 \mathrm{~cm}$ globes and (b) comparison of measurements curves between both devices.

WBGT $T_{\text {outdoor,9cm_calibrated }}=0.9912$ WBGT $T_{\text {outdoor }, 9 \mathrm{~cm}}+0.0292$ Equation 13

Table 1 summarizes the RMSE for the WBGT, MRT and globe temperature, using as a reference the measurements made by the standardized $15 \mathrm{~cm}$ globe device.

Table 1. Error analysis between calibrated proposed prototype and standardized heat stress monitor

\begin{tabular}{lcc}
\hline \multicolumn{1}{c}{ Measurement } & \multicolumn{2}{c}{ RMSE } \\
& Not-calibrated & Calibrated \\
\hline$t_{g}$ & 1.93 & 1.76 \\
WBGT & 0.39 & 0.35 \\
\multirow{2}{*}{ Mean radiant temperature (MRT) } & 3.81 & 3.33 \\
\hline
\end{tabular}

According to the summary shown in Table 1, without error correction, the RMSE of Globe Temperature, WBGT, and MRT was respectively 1.93, 0.39 and 3.81. After applying the error correction equation, RMSE was respectively 1.76, 0.35 and 3.33, which means an improvement in the error of $9 \%, 9 \%$, and $13 \%$ respectively.

\section{Conclusion}

When calibrating the $9 \mathrm{~cm}$ globe by means of equations obtained from linear regression, it is observed that improvements in measurements for Globe Temperature, WBGT, and MRT reach $17,20 \%$ and 24 respectively. This demonstrates that obtaining linear regression calibration curves from measured data over nearly 5 months could be an effective mean of 
obtaining accurate values for WBGT, MRT, and globe temperature measurements using a $9 \mathrm{~cm}$ globe prototype.

\section{Acknowledgements}

This work was supported by the European Commission through GROW GREEN project (Agreement number: 730283 — GROW GREEN — H2020-SCC-2016-2017/H2020-SCCNBS-2stage-2016. http://growgreenproject.eu/)

\section{References}

Deschenes, O. (2014). Temperature, human health, and adaptation: A review of the empirical literature. Energy Economics, 46, 606-619. https://doi.org/10.1016/j.eneco.2013.10.013

Enander, A. E., \& Hygge, S. (1990). Thermal stress and human performance. Scandinavian Journal of Work, Environment and Health, 16(SUPPL. 1), 44-50. https://doi.org/10.5271/sjweh.1823

Fishman, R., Carrillo, P., \& Russ, J. (2019). Long-term impacts of exposure to high temperatures on human capital and economic productivity. Journal of Environmental Economics and Management, 221-238. https://doi.org/10.1016/j.jeem.2018.10.001

Gasparrini, A., Guo, Y., Sera, F., Vicedo-Cabrera, A. M., Huber, V., Tong, S., ... Armstrong, B. (2017). Projections of temperature-related excess mortality under climate change scenarios. The Lancet Planetary Health, 1(9), e360-e367. https://doi.org/10.1016/S2542-5196(17)30156-0

Hunter, Charles H., Minyard, C. Olivia (1999) ESTIMATING WET BULB GLOBE TEMPERATURE USING STANDARD METEOROLOGICAL MEASUREMENTS. Westinghouse Savannah River Company, Aiken, South Carolina

Maurya, P. K., Haque, N., Kumar, R., \& Diwakar, R. (2019). SELECTING A SUITABLE HEAT STRESS INDEX TO PROTECT CATTLE AND, (March), 18-21.

Mendaza, P. (1993). NTP 322: Valoración del riesgo de estrés térmico por índice WBGT. Instituto Nacional de Seguridad e Higiene En El Trabajo, (1), 1-6. Retrieved from http://www.insht.es/InshtWeb/Contenidos/Documentacion/FichasTecnicas/NTP/Fich eros/301a400/ntp_322.pdf

NTP 322: Valoración del riesgo de estrés térmico: índice WBGT, Ministerio de trabajo y asuntos sociales de España (1999)

UNE ISO 7726, U. I. (2002). Norma española UNE ISO 7726. 